\title{
Autotoxicity mechanism of Oryza sativa: transcriptome response in rice roots exposed to ferulic acid
}

Wen-Chang Chi ${ }^{1 \dagger}$, Yun-An Chen ${ }^{1,2 \dagger}$, Yu-Chywan Hsiung ${ }^{1}$, Shih-Feng Fu ${ }^{3}$, Chang-Hung Chou ${ }^{4}$, Ngoc Nam Trinh ${ }^{1}$, Ying-Chih Chen ${ }^{1}$ and Hao-Jen Huang ${ }^{1 *}$

\begin{abstract}
Background: Autotoxicity plays an important role in regulating crop yield and quality. To help characterize the autotoxicity mechanism of rice, we performed a large-scale, transcriptomic analysis of the rice root response to ferulic acid, an autotoxin from rice straw.

Results: Root growth rate was decreased and reactive oxygen species, calcium content and lipoxygenase activity were increased with increasing ferulic acid concentration in roots. Transcriptome analysis revealed more transcripts responsive to short ferulic-acid exposure (1- and 3-h treatments, 1,204 genes) than long exposure (24 h, 176 genes). Induced genes were involved in cell wall formation, chemical detoxification, secondary metabolism, signal transduction, and abiotic stress response. Genes associated with signaling and biosynthesis for ethylene and jasmonic acid were upregulated with ferulic acid. Ferulic acid upregulated ATP-binding cassette and amino acid/ auxin permease transporters as well as genes encoding signaling components such as leucine-rich repeat VIII and receptor-like cytoplasmic kinases VII protein kinases, APETALA2/ethylene response factor, WRKY, MYB and Zincfinger protein expressed in inflorescence meristem transcription factors.

Conclusions: The results of a transcriptome analysis suggest the molecular mechanisms of plants in response to FA, including toxicity, detoxicification and signaling machinery. FA may have a significant effect on inhibiting rice root elongation through modulating ET and JA hormone homeostasis. FA-induced gene expression of AAAP transporters may contribute to detoxicification of the autotoxin. Moreover, the WRKY and Myb TFs and LRR-VIII and $\mathrm{SD}-2 \mathrm{~b}$ kinases might regulate downstream genes under FA stress but not general allelochemical stress. This comprehensive description of gene expression information could greatly facilitate our understanding of the mechanisms of autotoxicity in plants.
\end{abstract}

Keywords: Allelochemical, Ferulic acid, Microarray, Protein kinase, Rice, Autotoxicity

\section{Background}

Monoculture of crops leads to decreased growth and yield in the next season, with autotoxicity the major culprit [1-3]. Autotoxicity occurs when a plant releases toxic chemical substances into the environment that inhibit germination and growth of conspecific plants [4]. Recently, an increasing number of reports have provided evidence for the role of autotoxicity in replant failure

\footnotetext{
*Correspondence: haojen@mail.ncku.edu.tw

${ }^{\dagger}$ Equal contributors

'Department of Life Sciences, National Cheng Kung University, No. 1 University Rd. 701, Tainan, Taiwan, ROC

Full list of author information is available at the end of the article
}

and soil sickness [1]. Autotoxicity is a common problem in continuous monocropping of rice [2] because decomposing rice straw is left in fallow fields [5]. A range of secondary metabolites in rice straws, such as phenolic acids [6] and a few flavones and terpenoids [7], are potent autotoxins.

Phenolic compounds are common in soils. Whitehead [8] reported that the concentration of phenolic compounds in rhizosphere soil solution may reach $90 \mathrm{ppm}$. Various phenolic compounds such as ferulic acid (FA), o-hydroxy phenyl acetic acid, and p-coumaric acid have been isolated from decomposing rice residues in soil [5].

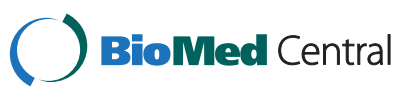


These compounds inhibit the growth of rice seedlings in the order of FA > p-coumaric acid > o-hydroxy phenyl acetic acid [9]. Exposure of plant roots to FA reduces water use [10], inhibits foliar expansion [11] and root elongation [12], and decreases nutrient uptake [13-15]. Further, FA exposure rapidly depolarizes root cell membranes, causing a generalized increase in membrane permeability, inducing lipid peroxidation and affecting certain enzymatic activities [16-18]. Ferulic acid may be esterified with cell wall polysaccharides, be incorporated into lignin structures, or form bridges that connect lignin with wall polysaccharides, thus resulting in cell wall rigidity and restriction of cell growth $[19,20]$. Ferulic acid affects cell wall-bound peroxidase (POD) and phenylalanine ammonia-lyase (PAL) activities, lignin content, and root growth in seedlings [21].

Several reports demonstrated that autotoxins induce oxidative stress in plants [22,23]. Reactive oxygen species (ROS) play a vital role in the plant defense against stresses and in cell growth and development $[24,25]$. Low concentrations of ROS, as a signal, can lead to repair of cellular damage, but high levels can lead to programmed cell death [26]. Calcium is a crucial regulator of growth and development in plants [27]. ROS-activated calcium channel activity is required during the growth of cells in the elongation zone of the root [28].

Both allelopathy and autotoxicity play important roles in regulating plant biodiversity and productivity [3]. Autotoxins can impact many physiological and biochemical reactions in plants such as rice, alfalfa, cucumber, tomato, corn, wheat, sugarcane $[1,23]$. The potential mechanisms underlying autotoxicity have been explored in alfalfa and cucumber [22,29]. In alfafa, cinnamic acid is a phenolic acid and the major autotoxin in leaves and root exudates [30]. In cucumber, autotoxins can inhibit the membrane $\mathrm{H}^{+}$-ATPase activity that drives the uptake of essential ions, other solutes and water [22]. However, our knowledge of an autotoxicity mechanism is poorly understood. Transcriptional profiling experiments using microarrays are being conducted to examine the effects of natural phytotoxins on the plant transcriptome [31]. Microarray analyses were used to analyze gene expression profiles of plants exposed to the allelochemicals $2(3 \mathrm{H})$ benzoxazolinone [32], fagomine, gallic acid, rutin [33], 3(3',4'-dihydroxyphenyl)-L-alanine [34], and juglone [35].

Rice (Oryza sativa L.) is a model for genomic research into the responses of monocot species to environmental stresses. In this study, we used FA as a rice-model autotoxin and used microarray assay to assess alterations in rice root gene expression induced by the autotoxin. We discuss the possible involvement of reactive oxygen species (ROS) and calcium in allelochemical signal transduction pathways. These data significantly expand on previous studies examining plant transcriptional responses to allelochemicals and provides a foundation for elucidating the autotoxicity mechanism of $O$. sativa, particularly the phytotoxic effect of decomposing rice residues in soil.

\section{Results}

Effect of FA on growth and root architecture of rice

To select an appropriate concentration of FA for stress treatments, we conducted a dose-response analysis of rice root growth 3 days after FA treatment (Figure 1A). Compared with the control, 25 ppm FA significantly reduced root growth. With 50 ppm FA, root growth was about half of the control growth, and with 200 ppm, growth was almost completely inhibited.

Compared with the control, 50 ppm FA inhibited crown root, lateral root and root hair formation. Both the number and length of lateral roots and root hairs were significantly reduced with $50 \mathrm{ppm}$ FA as compared with the control (Table 1).

\section{Ferulic acid rapidly induced ROS and calcium accumulation in rice roots}

To determine whether FA treatment induced ROS production, we labeled roots with the ROS-sensitive dye $\mathrm{CM}-\mathrm{H}_{2} \mathrm{DCFDA}$ (Figure $1 \mathrm{~B}$ ) or nitroblue tetrazolium (Additional file 1: Figure S1), then treated them with $50 \mathrm{ppm}$ FA for 1 or $3 \mathrm{~h}$. Ferulic-acid stress significantly increased the levels of dihydrodichlorofluorescein (DCF), and thus ROS, in roots (Figure 1B, Additional file 2: Figure S2). To determine whether FA treatment induced calcium accumulation, we used a calcium indicator, Oregon green 488 BAPTA-1, before FA treatment. Calcium level was significantly increased in root tip regions with $50 \mathrm{ppm}$ FA treatment for 1 or $3 \mathrm{~h}$ (Figure $1 \mathrm{C}$ and Additional file 2: Figure S2).

\section{Effect of FA on lipid peroxidation}

Ferulic-acid-induced oxidative damage of roots was positively confirmed by Schiff's staining in the meristem and elongation zone of roots (Additional file 3: Figure S3). Ferulic-acid-induced root oxidative damage was measured by LOX activity with non-denaturing PAGE. We detected 3 LOX isozymes in rice roots treated with 50 ppm FA for 3, 6, 12, and 24 h (Additional file 3: Figure S3).

\section{Expression profiling by microarray assay}

To identify genes and biological pathways associated with FA toxicity and tolerance in rice roots, we used large-scale expression profiling. RNA samples were collected from root tips early ( 1 and $3 \mathrm{~h}$ ) after FA treatment to examine rapid changes in global patterns of gene expression. We pooled RNA isolated from the two short ( 1 and $3 \mathrm{~h}$ ) FA exposures to maximize gene discovery. Mechanisms of adaptation after long-term (24 h) FA 


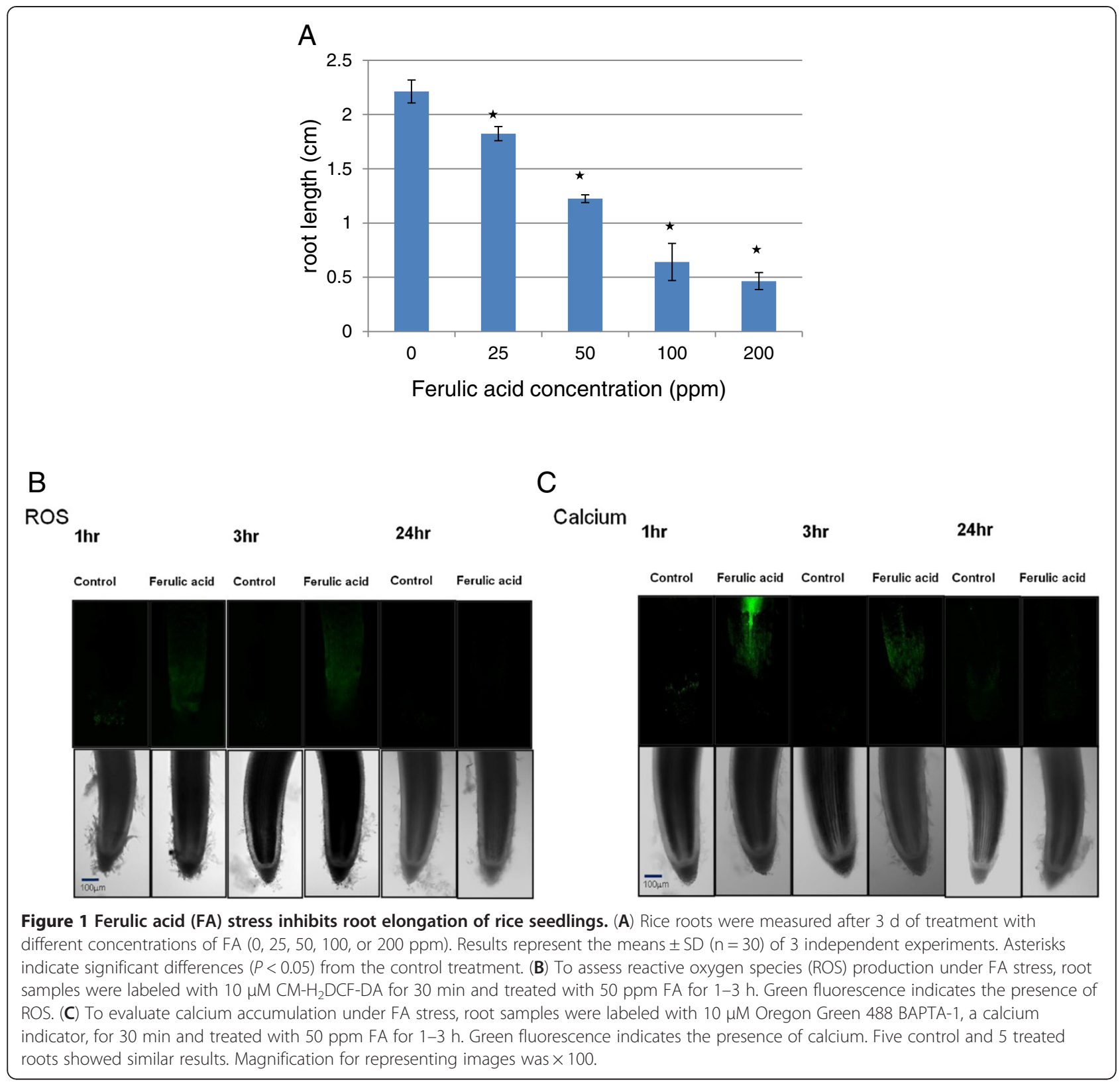

exposure are important, but the physiological and metabolic parameters measured after long treatment periods might be distorted by the severe toxic effects of FA. We aimed to understand the primary response to FA exposure as opposed to responses to nonspecific cellular damage.

We performed microarray assays with RNA extracted from roots treated with $50 \mathrm{ppm}$ FA after short (pooled from 1 - and 3-h treatments) and long ( $24 \mathrm{~h}$ ) exposure. This FA level is comparable to that found in rice-field soils $[8,36]$. In all, 1,204 genes were responsive to short FA exposure and 176 to long exposure. After short FA treatment, 972 genes were upregulated (FDR $<0.1$, fold change $\geq 2$ ) and 232 were downregulated (FDR $<0.1$, fold change $\leq 0.5$ ) (Additional file 4: Table S1).

We used GO analysis [37] to determine the functions of the 972 upregulated genes (Table 2, Additional file 5: Table S2). The most significantly enriched GO term was "response to stress" (GO:0006950, FDR 2.00E-47). Other enriched terms were "phenylpropanoid metabolic process" (GO:0009698, FDR 2.10E-07), "transmembrane transport" (GO:0055085, FDR 1.10E-12), "proteolysis" (GO:0006508, FDR 1.30E-14), "cell wall macromolecule metabolic process" (GO:0044036, FDR 6.10E-13) and "signal transduction" (GO:0007165, FDR 6.30E-05). For 
Table 1 Effect of ferulic acid treatment on number and length of crown root, lateral root and root hairs in rice

\begin{tabular}{|c|c|c|}
\hline Character $^{a}$ & Water & 50 ppm FA \\
\hline Crown root number & $6.93 \pm 0.88$ & $2.93 \pm 0.70$ \\
\hline Lateral root number/seedling & $20.73 \pm 2.63$ & $6.67 \pm 1.54$ \\
\hline Lateral root length (mm) & $6.15 \pm 0.93$ & $2.45 \pm 0.60$ \\
\hline Root hair number/mmb & $73.5 \pm 6.50$ & $40.1 \pm 3.07$ \\
\hline Root hair length $(\mu \mathrm{m})^{c}$ & $599.05 \pm 30.34$ & $205.55 \pm 27.29$ \\
\hline
\end{tabular}

${ }^{a}$ Number and length of root hairs on seminal root measured after $24 \mathrm{~h}$ FA treatment; other characters were determined on seedlings after 3-day FA treatment. Data are mean \pm SD.

b Number of root hairs from one side of 1-mm sections at the root hair zone (3-4 $\mathrm{mm}$ behind the root tip) on seminal roots. Data are mean of 10 seedlings. c Length of the 20 longest root hairs from the root hair zone of each seminal root. Data represent the mean of 10 seedlings.

molecular function, the significant GO terms were "kinase activity" (GO:0016301, 1.10E-32), "calcium ion binding" (GO:0005509, FDR 7.80E-23), "transcription factor activity" (GO:0003700, FDR 9.00E-19), and "chitinase activity" (GO:0004568, FDR 1.00E-09).

These observations were further supported by comparison of metabolism genes with use of MapMan. The genes encoding enzymes related to detoxification were cytochrome P450, UDP glycosyltransferases, and glutathione-S -transferases (Figure 2A). RT-PCR validated the microarray findings (Additional file 6: Figure S4).

\section{Expression profiles of root architecture-related genes}

To investigate the involvement of root architecture related genes in FA-induced stress, we analyzed the global expression profiles of genes related to 3 such gene families (Table 3). In total, 3 of the 18 root architecture related genes were slightly downregulated by FA (FDR < $0.1)$. FA repressed the expression of two lateral-root genes (ARF-16, Os06g0196700, downregulated 1.7-fold; OsCel9C, Os05g0212300, downregulated 1.6-fold) and one root-hair-related gene (OsCSLD1, Os10g0578200, downregulated 1.5 -fold) in rice roots (Table 3 ).

\section{Polysaccharide and cell wall metabolism}

To investigate the involvement of cell-wall-related genes in FA-induced stress, we analyzed the global expression profiles of genes related to 34 such gene families (Additional file 7: Table S3). In total, 30 of the 639 cell-wall-related genes showed significant responses to FA: 16 were upregulated and 14 downregulated. Upregulated genes predominantly belonged to the expansins (EXP), yieldins (GH18), xyloglucan endotransglycosylases/hydrolases $(\mathrm{XTH})$, beta-galactosidases (BGAL), glycoside hydrolases 17 (GH17), pectin acetylesterases (PAE). and glycosyl transferases 21A (GT31a).

\section{Expression profiles of ROS-related genes}

We analyzed the global expression profiles of genes related to 15 ROS-related gene families (Table 4, Additional file 8: Table S4). Among the 343 ROS response-network genes spotted on our arrays, transcripts of 270 showed changed expression after FA treatment (Additional file 8: Table S4): 55 were significantly regulated, 51 upregulated and four downregulated. The genes included alternative oxidases (AOX), glutathione peroxidase (GPx), glutathione reductase (GR), glutaredoxins (Grx), glutathioneS-transferases (GST), monodehydroascorbate reductase (MDAR), class III peroxidase (Prx), peroxiredoxin (PrxR), respiratory burst oxidase homolog (Rboh; NADPH oxidase), and thioredoxin (Trx). Almost all AOX genes were induced by FA, and 25 of the 79 GST genes were significantly upregulated by FA.

\section{Expression profiles of transporter genes}

In the rice genome, transporter families are grouped by mode of transport and energy-coupling mechanism into four types: ATP-dependent transporters, secondary transporters, ion channels, and unclassified transporters with unknown mechanisms of action. Among 1,286 transporter-related genes, 1,113 were present on our arrays, and 64 were significantly upregulated with FA treatment (Table 5, Additional file 9: Table S5). Nearly all of the transporters responding to FA were ATPdependent and secondary transporters. Transporters with changed expression were 17 of the 130 ATP-binding cassette $(\mathrm{ABC})$ transporters and three of the P-type ATPase (P-ATPase) transporters. The major facilitator superfamily (MFS) is the largest family of secondary transporters in the rice genome. Ferulic-acid treatment upregulated nine MFS genes and downregulated two. Transcripts for five proton-dependent oligopeptide transporter (POT) genes and five amino acid/auxin permease (AAAP) genes were upregulated. In addition, four of $123 \mathrm{drug} /$ metabolite transporter (DMT) genes belonging to secondary transporters were upregulated by FA treatment.

These observations were further supported by comparison of metabolism genes by use of MapMan. Genes encoding ATP-binding cassette-type and AAAP transporters were differentially regulated in the early ( 1 and $3 \mathrm{~h}$ ) response to FA (Figure 2B). MapMan analysis revealed that AAAP transporters were significantly upregulated by FA treatment.

\section{Expression profiles of phytohormone-related genes}

Among 324 phytohormone-related genes, 297 were present on our arrays, and 25 were significantly upregulated with FA treatment (Table 6, Additional file 10: Table S6). One jasmonic acid (JA) biosynthesis gene, OsAOS2 (Os03g0767000) and six JA signaling genes (Os03g0180900, Os10g0392400, Os03g0402800, Os03g01 
Table 2 Gene ontology analysis of 972 up-regulated genes

\begin{tabular}{lccc}
\hline GO ID & GO term & Query item & Background item \\
\hline & bDR p-value
\end{tabular}

Regulation of biological process

regulation of metabolic process

GO:0080090

GO:0045449

GO:0060255

GO:0010556

GO:0010468

GO:0009889

GO:0051171

regulation of cellular process

GO:0007165

GO:0007242

Biological regulation

GO:0065008

Multi-organism process

GO:0051707

GO:0009617

Cellular process

cellular response to stimulus

GO:0070887

GO:0055085

Metabolic process

primary metabolic process

GO:0005975

GO:0005976

GO:0006022

GO:0006030

GO:0016052

GO:0006629

GO:0019538

GO:0006508

secondary metabolic process

GO:0006721

GO:0016101

GO:0009698

macromolecule metabolic process

GO:0019538

GO:0043412

GO:0006464

GO:0044036

GO:0016998

GO:0010467 cellular response to chemical stimulus transmembrane transport

response to other organism

response to bacterium

9

6

39

7

4.80E-07

3.80E-09

0.00013

1.10E-12

$\begin{array}{cccc}\text { carbohydrate metabolic process } & 37 & 138 & 3.60 \mathrm{E}-29 \\ \text { polysaccharide metabolic process } & 12 & 57 & 1.10 \mathrm{E}-08 \\ \text { aminoglycan metabolic process } & 6 & 21 & 1.70 \mathrm{E}-05 \\ \text { chitin metabolic process } & 6 & 21 & 1.70 \mathrm{E}-05 \\ \text { carbohydrate catabolic process } & 17 & 45 & 1.10 \mathrm{E}-16 \\ \text { lipid metabolic process } & 21 & 81 & 1.20 \mathrm{E}-16 \\ \text { protein metabolic process } & 80 & 487 & 4.30 \mathrm{E}-44 \\ \text { proteolysis } & 23 & 126 & 1.30 \mathrm{E}-14\end{array}$

$\begin{array}{cccc}\text { terpenoid metabolic process } & 5 & 54 & 0.025 \\ \text { diterpenoid metabolic process } & 5 & 35 & 0.0036 \\ \text { phenylpropanoid metabolic process } & 6 & 11 & 2.10 \mathrm{E}-07\end{array}$

$$
\begin{aligned}
& \text { protein metabolic process } \\
& \text { macromolecule modification } \\
& \text { protein modification process }
\end{aligned}
$$

487

4.30E-44

cell wall macromolecule metabolic process

cell wall macromolecule catabolic process
$3.10 \mathrm{E}-31$

6.10E-13

8.60E-07

$3.50 \mathrm{E}-26$ gene expression 
Table 2 Gene ontology analysis of 972 up-regulated genes (Continued)

GO:0009059 macromolecule biosynthetic process

Establishment of localization

transport

GO:0006811

ion transport
cation transport
metal ion transport

GO:0006812

GO:0030001

metal ion transport

Response to stimulus

GO:0009719

response to endogenous stimulus

response to abiotic stimulus

response to biotic stimulus

response to stress

defense response

GO:0009628

GO:0009607

GO:0006950

GO:0006952

GO:0006979

response to oxidative stress

GO:0042221

response to chemical stimulus

response to organic substance

0.0075

9.70E-05

4.10E-12

2.00E-47

3.40E-13

GO:0010033

molecular function

Molecular transducer activity

GO:0004871

signal transducer activity

Transporter activity

substrate-specific transporter activity

GO:0022891

GO:0015075

GO:0008324

transmembrane transporter activity

GO:0016820

hydrolase activity, acting on acid anhydrides,

GO:0042626

$$
\begin{gathered}
\text { substrate-specific transmembrane transporter } \\
\text { ion transmembrane transporter activity }
\end{gathered}
$$

14

active transmembrane transporter activity

GO:0015291

secondary active transmembrane transporter

2.20E-06

GO:0015399

primary active transmembrane transporter activity

Antioxidant activity

GO:0004601

$$
\begin{gathered}
\text { peroxidase activity } \\
\text { transcription factor activity } \\
\text { monooxygenase activity } \\
\text { dioxygenase activity } \\
\text { disulfide oxidoreductase activity }
\end{gathered}
$$

\section{Catalytic activity}

oxidoreductase activity

GO:0004497

GO:0051213

GO:0015036

\section{transferase activity}

GO:0016757

GO:0016758

GO:0016772

transferase activity, transferring glycosyl groups 
Table 2 Gene ontology analysis of 972 up-regulated genes (Continued)

\begin{tabular}{|c|c|c|c|c|}
\hline GO:0004672 & protein kinase activity & 42 & 235 & $1.40 \mathrm{E}-25$ \\
\hline GO:0016301 & kinase activity & 51 & 261 & 1.10E-32 \\
\hline \multicolumn{5}{|c|}{ hydrolase activity } \\
\hline GO:0016798 & hydrolase activity, acting on glycosyl bonds & 25 & 87 & $6.40 \mathrm{E}-21$ \\
\hline GO:0004553 & hydrolase activity, hydrolyzing O-glycosy & 24 & 85 & $6.50 \mathrm{E}-20$ \\
\hline GO:0004568 & chitinase activity & 9 & 21 & 1.00E-09 \\
\hline \multicolumn{5}{|l|}{ Binding } \\
\hline \multicolumn{5}{|c|}{ carbohydrate binding } \\
\hline GO:0005529 & sugar binding & 6 & 10 & $9.10 \mathrm{E}-08$ \\
\hline \multicolumn{5}{|c|}{ nucleic acid binding } \\
\hline \multicolumn{5}{|l|}{ ion binding } \\
\hline GO:0043169 & cation binding & 126 & 175 & $6.50 \mathrm{E}-166$ \\
\hline GO:0046872 & metal ion binding & 111 & 173 & $1.60 \mathrm{E}-137$ \\
\hline GO:0046914 & transition metal ion binding & 80 & 132 & 9.80E-97 \\
\hline GO:0008270 & zinc ion binding & 30 & 89 & $3.60 \mathrm{E}-27$ \\
\hline GO:0005507 & copper ion binding & 6 & 19 & $9.00 \mathrm{E}-06$ \\
\hline GO:0005509 & calcium ion binding & 20 & 39 & $7.80 \mathrm{E}-23$ \\
\hline
\end{tabular}

81100, Os03g0180800, and Os09g0439200) were upregulated by FA exposure; none were downregulated during the same time of exposure. MapMan analysis revealed that ethylene (ET) synthesis and signaling genes were significantly upregulated by FA treatment (Figure 2C).

\section{Expression profiles of signaling genes and TFs}

Perception and transmission of stress signals are important aspects of the plant response to environment stress. Protein kinases are crucial in these signaling pathways. The activation of signal transduction pathways connects the actions of protein kinases, TFs and the downstream stress-responsive genes. In total, 51 protein kinase genes were upregulated by FA, and 16 were downregulated (Figure 3A, Additional file 11: Table S7). Nearly all of the FA-responsive kinases were associated with the receptor-like kinase (RLK) family. In total, 40 RLK family genes were significantly upregulated and 15 were downregulated after short and long FA exposure. The leucinerich repeat VIII (LRR-VIII) and receptor-like cytoplasmic kinases VII (RLCK-VII) subfamilies of the RLK family were significantly upregulated with FA treatment.

We found 107 TFs significantly regulated by FA: 85 were significantly upregulated and 22 downregulated after short and long exposure. Transcription factors regulated by FA stress predominantly belong to the APETALA2/ET response factor (AP2/ERF), MYB, WRKY and Zinc-finger protein expressed in inflorescence meristem (ZIM) families (Figure 3B, Additional file 12: Table S8). From rice genome sequence data, 164, 129, 100 and 18 genes have been identified for the AP2/ERF, MYB, WRKY and ZIM families, respectively. In our rice roots,
FA induced 14 AP2/ERF, 11 MYB, 17 WRKY and 6 ZIM families.

\section{Transporters, TFs, and protein kinases specifically altered by $\mathrm{FA}$ and juglone}

We compared transporters, TFs, and protein kinases regulated by exposure to FA and to the ROS-generating allelochemical juglone (Figure 4). Genes encoding AAAP transporters responded relatively specifically to FA (Additional file 13: Table S9). Comparison of the TFs induced by juglone after short FA exposure revealed that only half of the genes (48 of 84) reported in our previous study [35] showed changed expression in this study (Additional file 14: Table S10). The WRKY and Myb TFs responded significantly to FA stress. Comparison of the protein kinase genes induced by juglone revealed that the LRR-VIII and SD-2b families responded significantly to FA stress (Additional file 15: Table S11).

\section{Discussion}

Autotoxicity is intraspecific allelopathy and plays an important role in plant growth inhibition and structuring plant communities [1]. Here, we observed that treatment with $50 \mathrm{ppm}$ of the autotoxic chemical FA inhibited rice root length by $50 \%$ (Figure 1). Plant growth as well as response to stress is controlled by phytohormones [38]. Our microarray assay revealed changed expression of ET and JA biosynthesis and signaling genes in rice roots with FA treatment (Table 6). Xu et al. [39] reported that the combination of ET and JA synergistically induced the expression of defense genes in plants. Hua and Meyerowitz [40] and Staswick et al. [41] reported that JA and ET treatment 


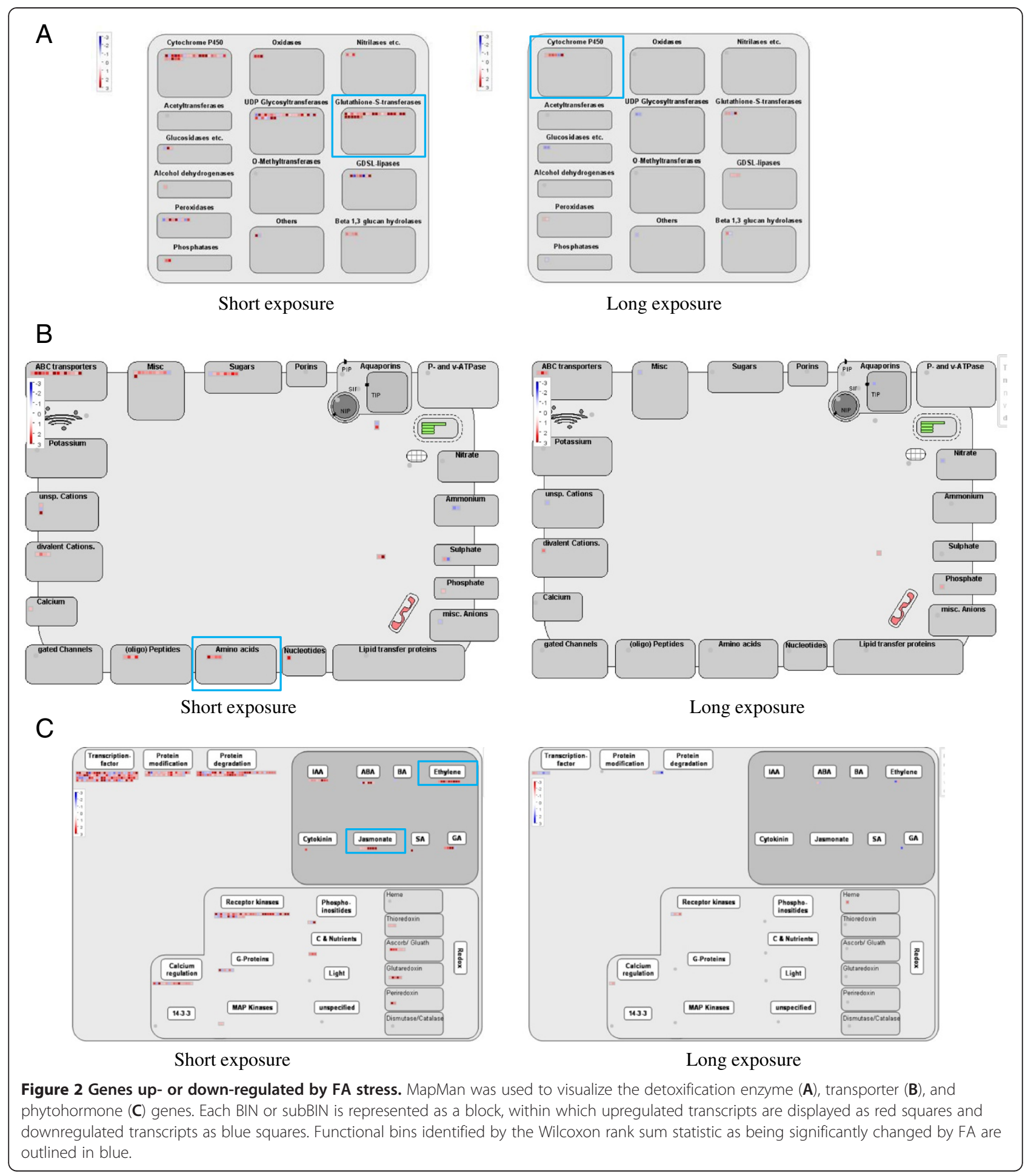

inhibited plant root elongation. Our results suggest that these two hormones may be involved in FA-induced inhibition of root growth in rice. In addition, we found that FA inhibited crown root, lateral root and root hair formation. FA repressed the expression of two lateral-root genes (ARF16, Os06g0196700; OsCel9C, Os05g0212300) and one root- hair-related gene in rice roots (OsCSLD1, Os10g0578200) (Table 3). Examination of the RiceXPro database revealed that JA repressed the expression of these genes (ARF-16, OsCel9C and OsCSLD1) [42]. Therefore, our results suggest that JA may involve in FA-induced morphogenic response in roots by regulating these root architecture- related genes. 
Table 3 List of rice genes associated with crown root, lateral root, root hair formation after FA exposures

\begin{tabular}{|c|c|c|c|c|c|}
\hline $\begin{array}{l}\text { Gene } \\
\text { name }\end{array}$ & $\begin{array}{l}\text { RAB-DB } \\
\text { Locus ID }\end{array}$ & TIGR Locus ID & $\begin{array}{l}\text { Short exposures } \\
\text { Fold change }^{a}\end{array}$ & $\begin{array}{l}\text { Long exposures } \\
\text { Fold change }^{\mathrm{a}}\end{array}$ & Description \\
\hline \multicolumn{6}{|c|}{ Crown root-related genes } \\
\hline OsCRL1 & Os03g0149000 & LOC_Os03g05500 & -1.09 & 1.15 & $\begin{array}{l}\text { Protein of unknown function DUF260 domain } \\
\text { containing protein. }\end{array}$ \\
\hline OsCRL4 & Os03g0666100 & LOC_Os03g46330 & -1.21 & -1.04 & SEC7-like domain containing protein. \\
\hline OsCRL5 & Os07g0124700 & LOC_Os07g03250 & 1.64 & 1.06 & $\begin{array}{l}\text { ANT (Ovule development protein } \\
\text { aintegumenta). }\end{array}$ \\
\hline OSARL1 & Os03g0149100 & LOC_Os03g05510 & & & \\
\hline WOX11 & Os07g0684900 & LOC_Os07g48560 & 1.86 & -1.39 & Homeobox domain containing protein. \\
\hline \multicolumn{6}{|c|}{ Lateral root-related genes } \\
\hline ARF-16 & Os06g0196700 & LOC_Os06g09660 & $-1.73^{*}$ & $-1.43^{*}$ & Auxin response factor 1 . \\
\hline AUX/IAA-1 & Os01g0178500 & LOC_Os01g08320 & $1.88^{*}$ & -1.20 & AUX/IAA protein family protein. \\
\hline AUX/IAA-11 & Os03g0633500 & LOC_Os03g43400 & 1.07 & -1.40 & $\begin{array}{l}\text { Auxin-responsive protein IAA17 (Indoleacetic } \\
\text { acid-induced protein 17) (Auxin response 3). }\end{array}$ \\
\hline AUX/IAA-13 & Os03g0742900 & LOC_Os03g53150 & 1.22 & -1.04 & AUX/IAA protein family protein. \\
\hline AUX/IAA-23 & Os06g0597000 & LOC_Os06g39590 & $1.77^{*}$ & -1.07 & $\begin{array}{l}\text { Auxin-responsive protein IAA14 (Indoleacetic } \\
\text { acid-induced protein 14) (SOLITARY-ROOT } \\
\text { protein). }\end{array}$ \\
\hline AUX/IAA-29 & Os12g0601400 & LOC_Os12g40900 & $1.16^{*}$ & -1.28 & Auxin-responsive protein (Aux/IAA) (Fragment). \\
\hline OsCelgC & Os05g0212300 & LOC_Os05g12150 & $-1.59^{*}$ & $1.43^{*}$ & Endo-beta-1,4-glucanase precursor (EC 3.2.1.4). \\
\hline \multicolumn{6}{|c|}{ Root hair-related genes } \\
\hline OsEXPA30 & Os10g0535900 & LOC_Os10g39110 & & & \\
\hline OsRHL1 & Os06g0184000 & LOC_Os06g08500 & & & \\
\hline OsCSLD1 & Os10g0578200 & LOC_Os10g42750 & 1.47 & $-1.94^{*}$ & Cellulose synthase-9. \\
\hline OsEXPA17 & Os06g0108600 & LOC_Os06g01920 & & & \\
\hline OsEXPB5 & Os04g0552200 & LOC_Os04g46650 & 1.22 & 1.11 & Beta-expansin 5. \\
\hline OSAPY1 & Os07g0682800 & LOC_Os07g48430 & 1.35 & -1.05 & Apyrase. \\
\hline
\end{tabular}

${ }^{a}$ The fold change in expression of each gene after FA treatment was calculated by the mean from 3 biological replicates and false discovery rate $<0.1$ is shown with a asterisk.

In general, cell walls become lignified when cell expansion decreases or when the cell is under stress [43]. Previous study indicated that lignification may be an important step in root growth reduction in FA-stressed soybean [21]. Our FA treatment upregulated genes involved in the cell-wall macromolecule metabolic process (GO:0044036, FDR 6.10E-13), particularly cell-wall reassembly. The expression of cell-wall-related genes, most notably the expansins, was enriched by FA treatment. Cosgrove found that expansins are a group of wall proteins that induce wall stress relaxation and extension [44]. Increased expansin gene activity may be involved in stress relaxation in FA-treated roots.

Increased ROS levels are an important component of the stress induced by allelochemicals [45]. Ferulic acid modifies various oxidative reactions in vitro by acting as a substrate, activator or inhibitor depending on the concentration $[46,47]$. Reactive oxygen species are toxic to plant tissues and can trigger cell growth inhibition and cell death. In addition, they may act as signal molecules involved in triggering tolerance against various environmental stresses. In this study, FA rapidly induced ROS production in rice roots. Ferulic acid-induced lipid peroxidation of roots was positively confirmed by Schiff's reagent staining (Additional file 3: Figure S3). We found a steady increase in LOX activity in response to FA (Additional file 3: Figure S3). Thus, FA may increase ROS accumulation, lipid peroxidation, and LOX activity to affect cell integrity in rice roots and contribute to FAinduced root growth inhibition.

Many studies have provided evidence that ROS signaling is integrated with calcium signaling networks in plants. Saijo et al. [48] and Martín and Busconi [49] demonstrated rapid increase in cytoplasmic calcium concentrations in plant cells in response to multiple stress stimuli. The change in cytoplasmic calcium concentrations is critical for activating various defense responses [50]. We found that FA increased calcium levels in rice roots. Thus, ROS and calcium may act as early second messengers in the transcriptional activation of an 
Table 4 Ferulic acid-responsive transcripts related to ROS

\begin{tabular}{|c|c|c|c|c|c|c|c|}
\hline \multirow[b]{2}{*}{ Functional categories } & \multirow[b]{2}{*}{ In genome } & \multirow[b]{2}{*}{ On arrary } & \multirow[b]{2}{*}{ Detected } & \multicolumn{2}{|c|}{ Short exposures } & \multicolumn{2}{|c|}{ Long exposures } \\
\hline & & & & Increased $^{a}$ & Decreased & Increased & Decreased \\
\hline Reactive oxygen species (ROS) network & 343 & 323 & 270 & 51 & 4 & 5 & 2 \\
\hline AOX (Alternative oxidases) genes & 4 & 4 & 4 & $4^{*}$ & 0 & 0 & 0 \\
\hline APx (Ascorbate peroxidase) genes & 11 & 11 & 8 & 0 & 0 & 0 & 0 \\
\hline Cat (Catalase) genes & 3 & 3 & 3 & 0 & 0 & 0 & 0 \\
\hline DiOx (Alpha-dioxygenase) & 1 & 1 & 1 & 0 & 0 & 0 & 0 \\
\hline Ferritin genes & 2 & 2 & 2 & 0 & 0 & 0 & 0 \\
\hline GPx(Glutathione peroxidase) genes & 5 & 5 & 5 & 1 & 0 & 0 & 0 \\
\hline GR (Glutathione reductase) genes & 3 & 3 & 3 & 2 & 0 & 0 & 0 \\
\hline Grx (Glutaredoxins) genes & 27 & 22 & 17 & 5 & 0 & 0 & 0 \\
\hline GST (Glutathione-S-transferases) genes & 79 & 74 & 67 & $25^{*}$ & 0 & 3 & 2 \\
\hline MDAR (monodehydroascorbate reductase) genes & 15 & 14 & 8 & 2 & 0 & 0 & 0 \\
\hline Prx (Class III Peroxidase) genes & 138 & 130 & 103 & $7^{*}$ & 4 & 2 & 0 \\
\hline PrxR(Peroxiredoxin) genes & 8 & 8 & 7 & 2 & 0 & 0 & 0 \\
\hline $\begin{array}{l}\text { Rboh (Respiratory burst oxidase homolog; NADPH } \\
\text { oxidase) genes }\end{array}$ & 9 & 9 & 7 & 1 & 0 & 0 & 0 \\
\hline SOD (superoxide dismutase) genes & 8 & 8 & 8 & 0 & 0 & 0 & 0 \\
\hline Trx (thioredoxin) genes & 30 & 29 & 27 & 2 & 0 & 0 & 0 \\
\hline
\end{tabular}

${ }^{a}$ Functional categories of genes, total number of genes found within the rice genome, numbers of genes present on and detected on arrays, and numbers of genes showing significant differences (FDR $<0.1)$ in transcript abundance are shown in rows and columns labeled accordingly.

ROS families that are overrepresented in the response group are shown with asterisks $(P<0.05)$.

array of defense-related genes in rice roots under FA stress.

Conjugated forms of xenobiotics can be recognized by specific membrane-associated transporters in the final detoxification phase [32]. Our GO analysis notably revealed the term "primary active transmembrane transporter activity". We found 64 membrane-transporter-like sequences induced by FA, including 17 putative $A B C$, nine MFS, and five AAAP transporters. In plants, $A B C$ and MFS transporters represent different multidrug efflux protein superfamilies associated with resistance to xenobiotics [32]. The ABC transporters facilitate the movement of glutathionylated toxins and other substrates across biological membranes [51]. We found 17 and three $A B C$ transporter genes upregulated by short and long FA exposure, respectively. Thus, expression of $\mathrm{ABC}$ transporters, which work in conjunction with other detoxifying systems, was found primarily with early stages of FA stress. The AAAPs are efficient transporters of proline and betaine [52] that accumulate in higher plants under stress conditions such as drought, salinity, extreme temperatures, UV radiation, and heavy metals [53,54]. Previous reports have demonstrated a positive relationship between proline and betaine accumulation and plant stress tolerance $[55,56]$. Our observed induction of AAAPs by FA indicates their possible involvement in plant tolerance to autotoxin stress.
Protein kinases are important signaling molecules in the plant response to environment stress. Multiple plant RLK members are involved in the stress response [57-59]. Among 40 RLK genes we found upregulated with FA treatment, LRR-VIII and RLCK-VII subfamilies were identified as significantly participating in transcriptional regulation (Additional file 11: Table S7). The involvement of LRR-VIII and RLCK-VII in stress responses was previously reported [58]. Thus, differential expression of a number of transmembrane receptor kinases with FA exposure suggests that multiple receptors belonging to different families may have unique regulatory mechanisms.

Responses to abiotic stresses require the production of important regulatory proteins such as TFs to mediate the expression of downstream stress-responsive genes. We found that the major TFs, AP2/ERF, MYB, WRKY, and ZIM, were overrepresented in the response to FA. The AP2/ERF, MYB, and WRKY TFs have been isolated from different plants and are important candidates for the stress tolerance response; in rice, the overexpression of AP2/ERF, MYB, and WRKY conferred significant tolerance to abiotic stresses [60-63]. Transcription factors of ZIM have been intensively investigated because of the role of these proteins as key regulators of the jasmonate hormonal response in Arabidopsis and rice [64]. Here, we found that FA upregulated six ZIM genes. Overexpression of ZIM-3 (Os03g0180800), a stress-inducible gene, was 
Table 5 Ferulic acid-responsive transcripts related to transporter

\begin{tabular}{|c|c|c|c|c|c|c|c|}
\hline \multirow[b]{2}{*}{ Family name } & \multirow[b]{2}{*}{ In genome } & \multirow[b]{2}{*}{ On array } & \multirow[b]{2}{*}{ Detected } & \multicolumn{2}{|c|}{ Short exposures } & \multicolumn{2}{|c|}{ Long exposures } \\
\hline & & & & Increase ${ }^{a}$ & $\overline{\text { Decrease }}$ & Increase & $\overline{\text { Decrease }}$ \\
\hline \multicolumn{8}{|l|}{ ATP-dependent } \\
\hline ATP-binding Cassette (ABC) Superfamily & 130 & 115 & 80 & $17^{*}$ & 1 & 3 & 0 \\
\hline P-type ATPase (P-ATPase) Superfamily & 45 & 42 & 37 & 3 & 0 & 0 & 0 \\
\hline \multicolumn{8}{|l|}{ Ion channels } \\
\hline Ammonia Transporter Channel (Amt) Family & 12 & 8 & 7 & 0 & 2 & 0 & 0 \\
\hline Annexin (Annexin) Family & 9 & 6 & 6 & 1 & 0 & 1 & 0 \\
\hline Glutamate-gated Ion Channel (GIC) Family of Neurotransmitter & 21 & 12 & 10 & 1 & 0 & 1 & 0 \\
\hline Major Intrinsic Protein (MIP) Family & 37 & 33 & 24 & 0 & 0 & 0 & 1 \\
\hline \multicolumn{8}{|l|}{ Secondary transporter } \\
\hline Amino Acid/Auxin Permease (AAAP) Family & 63 & 52 & 41 & 5 & 0 & 0 & 0 \\
\hline Auxin Efflux Carrier (AEC) Family & 19 & 16 & 11 & 2 & 1 & 0 & 0 \\
\hline Amino Acid-Polyamine-Organocation (APC) Family & 27 & 22 & 20 & 1 & 0 & 0 & 0 \\
\hline Aromatic Acid Exporter (ArAE) Family & 14 & 13 & 6 & 1 & 0 & 1 & 0 \\
\hline Arsenite-Antimonite (ArsB) Efflux Family & 3 & 3 & 3 & 1 & 0 & 0 & 0 \\
\hline Ca2+:Cation Antiporter (CaCA) Family & 16 & 15 & 13 & 1 & 0 & 0 & 0 \\
\hline Chloride Carrier/Channel (CIC) Family & 9 & 9 & 8 & 0 & 1 & 0 & 0 \\
\hline Divalent Anion:Na + Symporter (DASS) Family & 7 & 7 & 5 & 1 & 0 & 0 & 0 \\
\hline Drug/Metabolite Transporter (DMT) Superfamily & 123 & 106 & 86 & 4 & 1 & 0 & 1 \\
\hline $\mathrm{K}+$ Transporter (Trk) Family & 7 & 7 & 2 & 1 & 0 & 0 & 0 \\
\hline Mitochondrial Carrier (MC) Family & 61 & 59 & 55 & 2 & 0 & 0 & 0 \\
\hline Major Facilitator Superfamily (MFS) & 151 & 133 & 103 & 9 & 2 & 1 & 1 \\
\hline $\begin{array}{l}\text { Multidrug/Oligosaccharidyl-lipid/Polysaccharide (MOP) } \\
\text { Flippase Superfamily }\end{array}$ & 57 & 44 & 34 & 5 & 1 & 0 & 0 \\
\hline Monovalent Cation:Proton Antiporter-2 (CPA2) Family & 20 & 18 & 4 & 1 & 0 & 1 & 0 \\
\hline Proton-dependent Oligopeptide Transporter (POT) Family & 86 & 74 & 50 & 5 & 0 & 0 & 0 \\
\hline Telurite-resistance/Dicarboxylate Transporter (TDT) Family & 9 & 8 & 4 & 0 & 1 & 1 & 0 \\
\hline Sulfate Permease (SulP) Family & 14 & 14 & 13 & 1 & 0 & 0 & 0 \\
\hline Zinc $\left(\mathrm{Zn}^{2+}\right)$-Iron $\left(\mathrm{Fe}^{2+}\right)$ Permease (ZIP) Family & 18 & 16 & 12 & 2 & 0 & 0 & 0 \\
\hline
\end{tabular}

${ }^{a}$ Functional categories of genes, total number of genes found within the rice genome, numbers of genes present on and detected on arrays, and numbers of genes showing significant differences (FDR $<0.1$ ) in transcript abundance are shown in rows and columns labeled accordingly. Transporter families that are overrepresented in the response group are shown with asterisks $(P<0.05)$.

Table 6 Ferulic acid-responsive transcripts related to phytohormones

\begin{tabular}{|c|c|c|c|c|c|c|c|c|}
\hline \multirow{2}{*}{\multicolumn{2}{|c|}{ Functional categories }} & \multirow[b]{2}{*}{ In genome } & \multirow[b]{2}{*}{ On arrary } & \multirow[b]{2}{*}{ Detected } & \multicolumn{2}{|c|}{ Short exposures } & \multicolumn{2}{|c|}{ Long exposures } \\
\hline & & & & & Increased $^{a}$ & Decreased & Increased & Decreased \\
\hline \multirow[t]{3}{*}{ Ethylene } & Total & 29 & 27 & 22 & 3 & 0 & 0 & 0 \\
\hline & Biosynthesis & 13 & 11 & 10 & 3 & 0 & 0 & 0 \\
\hline & Signaling & 16 & 16 & 12 & 0 & 0 & 0 & 0 \\
\hline \multirow[t]{3}{*}{$J A$} & Total & 38 & 34 & 34 & $7^{*}$ & 0 & 0 & 0 \\
\hline & Biosynthesis & 27 & 24 & 16 & 1 & 0 & 0 & 0 \\
\hline & Signaling & 11 & 10 & 10 & 6 & 0 & 0 & 0 \\
\hline
\end{tabular}

a Functional categories of genes, total number of genes found within the rice genome, numbers of genes present on and detected on arrays, and numbers of genes showing significant differences (FDR $<0.1)$ in transcript abundance are shown in rows and columns labeled accordingly.

Phytohormone families that are overrepresented in the response group are shown with asterisks. 

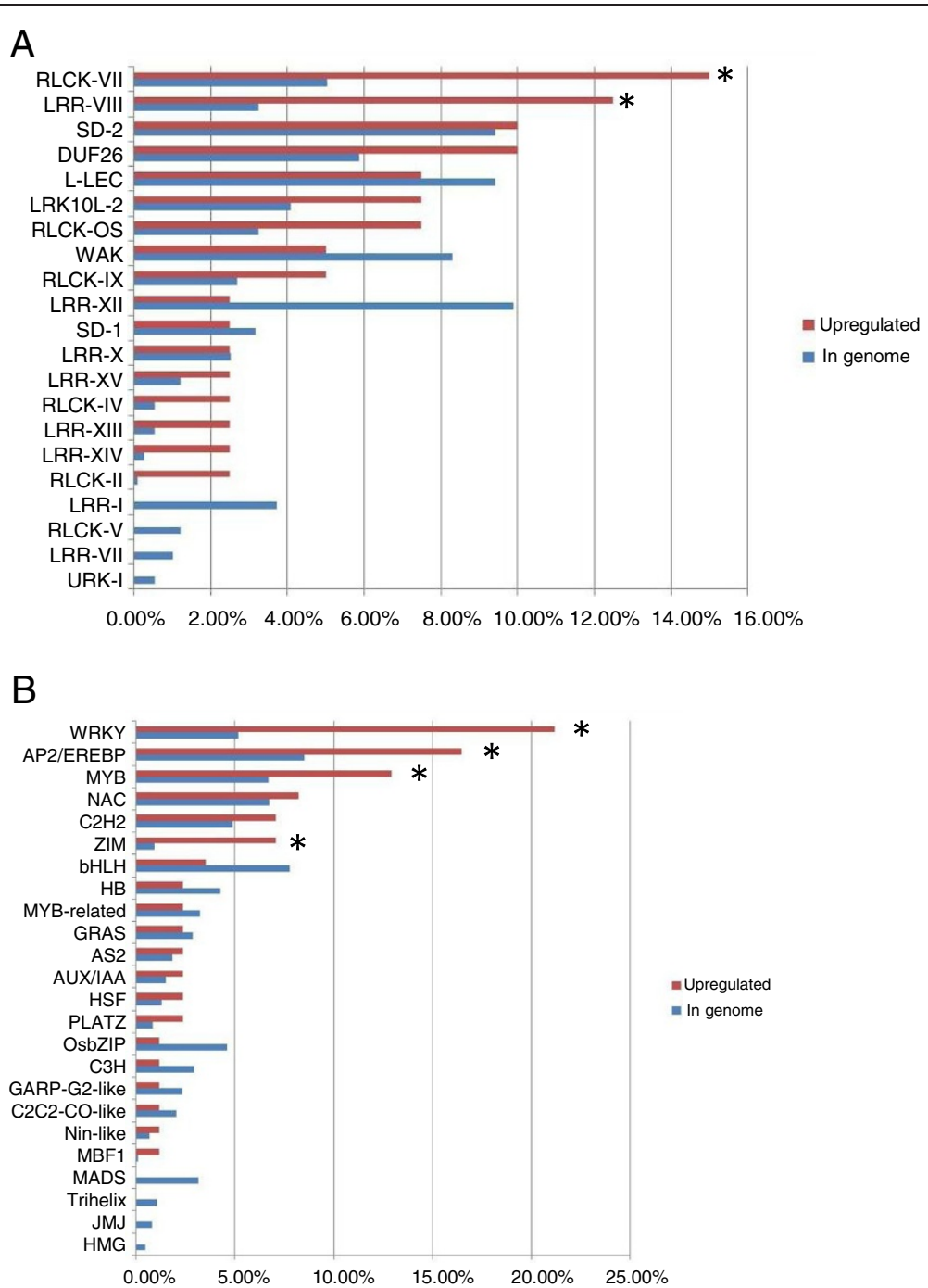

Figure 3 Family classifications of FA stress response genes. Twenty-one receptor like kinase (RLK) protein kinase families (A) and 24 transcription factor families (B) were regulated by FA stress. Red bars represent the percentage of upregulated genes (fold change $\geq 2 ;$ FDR $<0.1$ ) in each protein kinase or transcription factor family. Blue bars refer to the percentage of genes per kinase or transcription factor categories with respect to the entire number of kinases or transcription factors in the genome. Fisher's exact test was used to assess the significance of overrepresented protein kinase and transcription factor families. Asterisks indicate families that were significantly overrepresented in the response group $(P<0.05)$.

found to significantly increase tolerance to salt and dehydration stresses [64]. The observed induction of AP2/ ERF, MYB, WRKY, and ZIM TFs during FA treatment indicates their possible involvement in plant resistance to autotoxin stress.

Reactive oxygen species are secondary messengers for the activation of specific TFs. We found that FA induced ROS production. Therefore, we compared the set of our FA-regulated TFs to those regulated by exposure to juglone, an ROS-generating allelochemical [35]. Our results suggest that WRKY and Myb TFs and LRR-VIII and SD-2b kinases might regulate downstream genes under FA stress but not general allelochemical stress
(Figure 4). Moreover, 64 transporters were upregulated by FA, but only 31 transporters were upregulated by juglone. The number of upregulated genes encoding transporters was more under FA than juglone stress. Especially, the AAAP transporter family was regulated significantly by FA stress but not by juglone (Figure 4). The AAAPs are efficient transporters of osmoprotectants such as proline, glycinebetaine and gamma-aminobutyric acid [52] that accumulate in higher plants under stress conditions. This observation could be related to detoxification of the autotoxin in rice roots. The AAAP transporters may play an important role in the FA-triggered autotoxicity mechanism. 


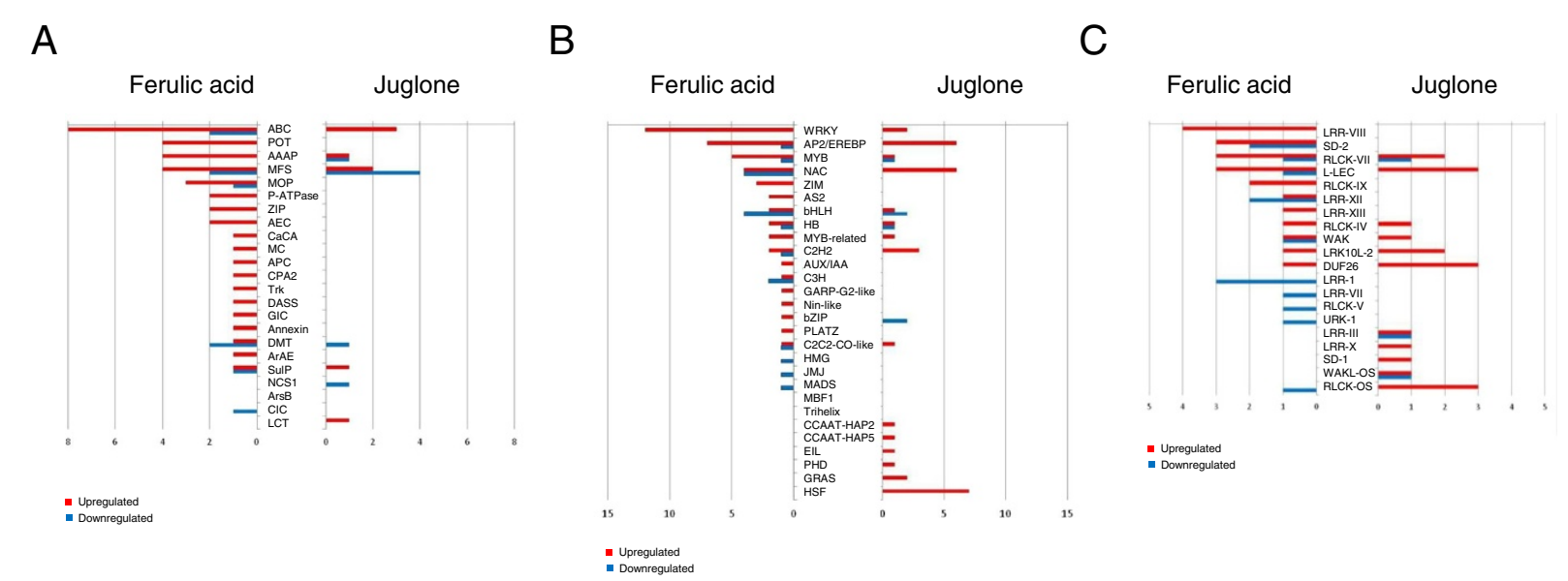

Figure 4 Comparison of gene regulation by FA and juglone. FA and juglone specific regulation of transporters (A), transcription factors (B), and protein kinases $(\mathbf{C})$. Genes repressed or activated by FA or juglone are in blue (fold change $\leq 0.5$ ) and red (fold change $\geq 2$ ), respectively.

\section{Conclusions}

FA may have a significant effect on inhibiting rice root elongation through ET and JA gene regulation. Detoxification enzymes such as cytochrome, GST, and ROS scavengers are involved in protecting against FA toxicity. Moreover, proteins involved in regulatory functions and signal transduction, including TFs, calcium-regulated proteins, and various protein kinases, play important roles in the response to FA stress (Figure 5). Future studies with rice mutants or overexpressors with altered expression of the genes identified in this work will be helpful to elucidate their biological significance and clarify new pathways involved in toxicity and tolerance to FA.

\section{Methods}

\section{Plant materials}

Rice plants (O. sativa L. cv. TN-67) were grown as previously described [65]. Rice seedlings were exposed to FA ( 25 to $200 \mathrm{ppm}$ ) for 1 to $24 \mathrm{~h}$. Control plants were treated with water in parallel for the indicated times.

\section{Analysis of growth}

Rice seeds were surface-disinfected with $2.5 \%$ (v/v) sodium hypochlorite (Katayama, Osaka, Japan) for $15 \mathrm{~min}$, then thoroughly washed in distilled water. Seeds were placed in 9-cm Petri dishes containing $20 \mathrm{ml}$ distilled water and left at $37^{\circ} \mathrm{C}$ in the dark. After $2 \mathrm{~d}$ of incubation, uniformly germinated seeds were transferred to Petri dishes with filter paper discs (Advantec, Tokyo) moistened with $10 \mathrm{ml}$ distilled water. Each Petri dish contained 15 germinated seeds grown at $27^{\circ} \mathrm{C}$ in the dark for $3 \mathrm{~d}$. Once the roots reached $0.2 \mathrm{~cm}$ in length, they were used for experiments of exposure to FA (Sigma, St. Louis, MO, USA) under sterile conditions in the same Petri dish. Ferulic acid was added at final concentrations of 0 to $200 \mathrm{ppm}$ for varying treatment durations. Root length was measured after $3 \mathrm{~d}$ of incubation at $26^{\circ} \mathrm{C}$ in darkness. Mean root length was obtained from 15 individual seedlings from at least 3 separate experiments. To determine the number of crown root and lateral roots, the number of all emerged lateral roots on seminal roots was counted by the naked eye. Root samples of 6-day-old rice seedlings were treated with FA for 3 days. The values of crown root and lateral root number represent the mean of 15 seedlings. The value of lateral root length represents the mean of 200 lateral roots. For root hair measurement, after 24-h FA treatment, the number and length of root hairs on the root hair zone immediately behind the root tip (3-4 mm behind the root tip) of seminal roots were determined by microscopy (Leica MZ125) (Leica Microsystems, Heerbrugg, Switzerland). To determine number of root hairs, the number of root hairs from one side of the root hair zone of seminal roots was counted. To determine the length of root hairs, the length of the 20 longest root hairs from the root hair zone of seminal roots was measured.

\section{Detection of ROS and calcium levels in rice roots}

Root samples of 6-day-old rice seedlings were labeled with $10 \mu \mathrm{M} \mathrm{CM}-\mathrm{H}_{2} \mathrm{DCF}-\mathrm{DA}$ (Molecular Probes, Eugene, OR, USA) or Oregon Green 488 BAPTA-1 (Molecular Probes) for $30 \mathrm{~min}$ to determine ROS or calcium levels, respectively, then treated with $50 \mathrm{ppm}$ FA for 1-3 h. Fluorescence images were visualized under a confocal microscope (EZ-C1; Nikon, Tokyo, Japan) with the 488$\mathrm{nm}$ laser line of an Ar laser (2 $\mathrm{mW}$ optical fiber output; 500-530 nm). Exposure times were equal for all samples.

\section{Purification of total RNA}

Total RNA was extracted from rice plants grown as described above [35] and treated with 50 ppm FA for 1$24 \mathrm{~h}$. Roots were separated from shoots, and total RNA 


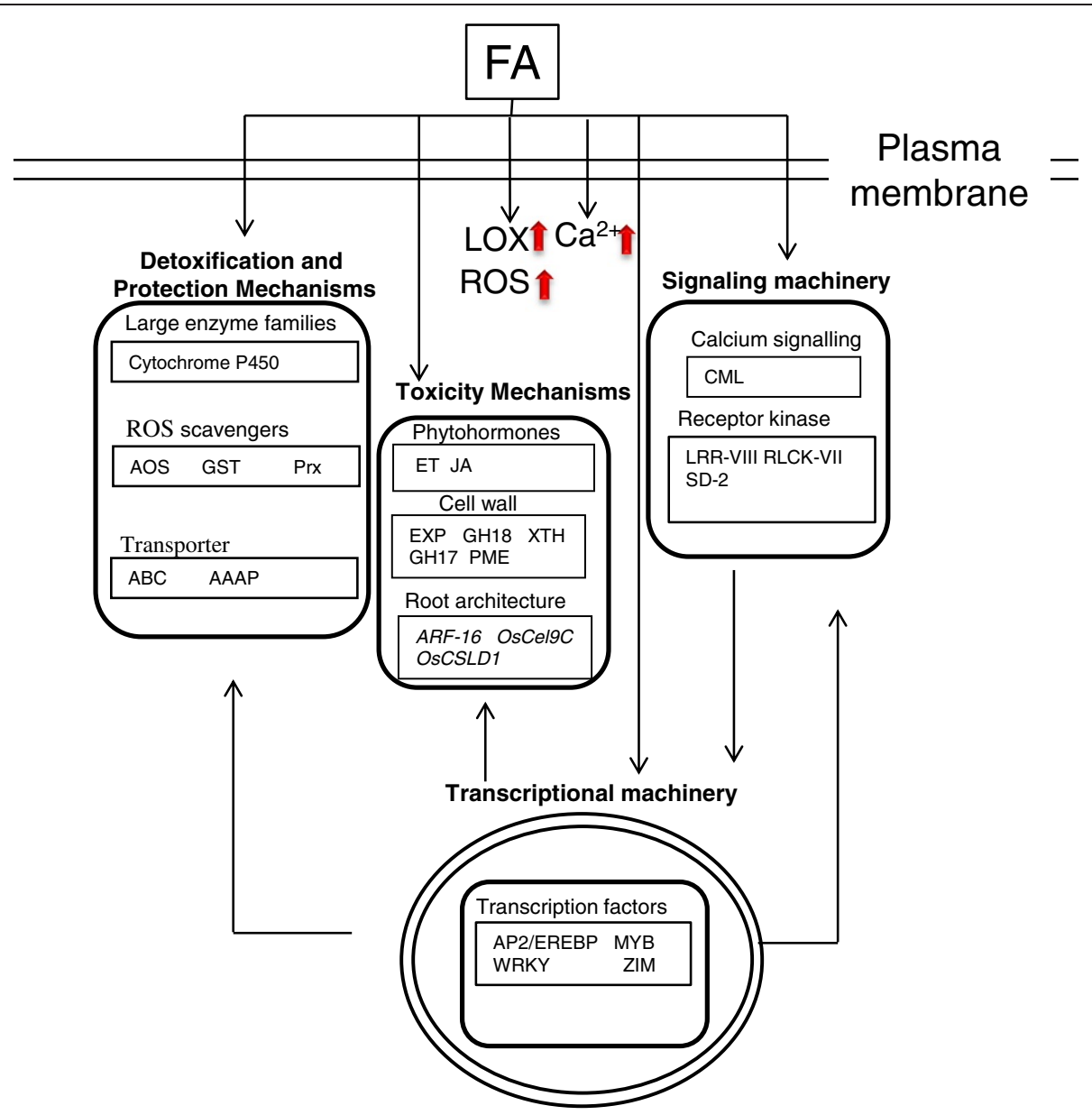

Figure 5 Molecular mode of action of the allelochemical FA in cellular processes and response/regulatory pathways.

was isolated from root tissues with use of the RNeasy Plant Mini kit (QIAGEN, Hilden, Germany). The RNA was further treated with DNase (QIAGEN) to eliminated DNA contamination. The concentrations of total RNA samples were measured with use of NanoDrop ND2000 (NanoDrop Technologies, Wilmington, DE, USA). The purity of RNA samples was determined by $\mathrm{OD}_{260 / 280}$ and $\mathrm{OD}_{260 / 230}$. RNA samples of more than $2 \mu \mathrm{g} / \mu \mathrm{l}$ concentration and high purity $\left(\mathrm{OD}_{260 / 280}>2, \mathrm{OD}_{260 / 230}>2\right)$ were used for microarray assay and RT-PCR.

\section{Microarray preparation and analysis}

Six-day-old rice seedlings were exposed to $50 \mathrm{ppm}$ FA for short ( 1 and $3 \mathrm{~h}$ ) or long ( $24 \mathrm{~h})$ durations, then RNA was isolated from root tips to examine rapid changes in global patterns of gene expression. We pooled RNA from the two short exposures to maximize gene discovery. RNA from water-treated (control) and FA-treated roots was used with the Agilent Rice Oligo microarray $(4 \times 44 \mathrm{~K}$, custom-made; Agilent Technologies, Palo Alto, CA, USA) for RNA labeling and microarray hybridizations involved 3 biological replicate samples.
For the microarray assay, $0.5 \mu \mathrm{g}$ total RNA was amplified by use of the Fluorescent Linear Amplification Kit (Agilent) and labeled with Cy3-CTP (control samples) or Cy5-CTP (FA-treated) (CyDye, PerkinElmer, Norwalk, CT, USA) during the in vitro transcription process. In total, $0.825 \mu \mathrm{g}$ Cy-labeled cRNA was fragmented to a mean size of about $50-100$ nt by incubation with fragmentation buffer (Agilent) at $60^{\circ} \mathrm{C}$ for $30 \mathrm{~min}$. The fragmented-labeled cRNA was then pooled and hybridized to the Rice Oligo DNA Microarray 44 K RAP-DB (G2519F\#15241; Agilent) at $60^{\circ} \mathrm{C}$ for $17 \mathrm{~h}$. After a washing and blow-drying with a nitrogen gun, microarrays were scanned with use of an Agilent microarray scanner at $535 \mathrm{~nm}$ for $\mathrm{Cy} 3$ and $625 \mathrm{~nm}$ for Cy5. Scanned images were analyzed with use of Feature Extraction v9.5.3 (Agilent), with LOWESS normalization.

Signal intensities were extracted with use of Feature Extraction v9.5.3. For statistical analysis, we excluded genes with signal intensities $<100$ in all experiments. Significant differences from 0 were identified by use of $t$ test with GeneSpringGX11 (Agilent). The BenjaminiHochberg false discovery rate (FDR) method was used to 
obtain $P$-values that were corrected for multiple testing. The fold change in expression of each gene after FA treatment was calculated by the mean from 3 biological replicates. Genes upregulated by FA treatment by more than two-fold (cutoff by FDR $<0.1$ ) were extracted. Each probe was considered an individual gene and annotated according to the Rice Annotation Project Data Base (RAP-DB; http://rapdb.dna.affrc.go. jp/; Rice Annotation Project 2007, 2008). The dye swap was not included. Three biological replicates were performed with 3 independent microarray slides for both short- and long-term FA treatments. Total RNA control samples were labeled with $\mathrm{Cy} 3$, and total RNA experimental samples (FA treatment) were labeled with Cy5.

FA-responsive genes were annotated according to the RAP-DB and TIGR Rice Genome Annotation Resource (http://rice.plantbiology.msu.edu/) [66] and were classified into functional categories by AgriGO gene ontology (GO) functional enrichment analysis [67]. For signaling, transcription factor (TF), and peroxidase functions, the lists of rice genes encoding protein kinases (1,467 genes), TFs (1,930 genes), the main ROS (343 genes), cell-wall-related genes (639 genes), and transporters (1,286 genes) were obtained from the Rice Kinase Database (http://rkd. ucdavis.edu) [68], the Database of Rice Transcription Factors (DRTF; http://drtf.cbi.pku.edu.cn/) [69], the peroxidase database (http://peroxibase.toulouse.inra.fr/) [70], Cell Wall Navigator (CWN; http://bioinfo.ucr.edu/projects/ Cellwall/index.pl) [71], and TransportDB (http://www. membranetransport.org) [72], respectively. Fisher's exact test $(P<0.05)[73]$ was used to assess the significance of overrepresented ROS, cell-wall, transporters, protein kinases and TFs in the list of regulated genes in the genome. The microarray data described in this study have been deposited in the Gene Expression Omnibus and are accessible with the series accession number [GEO: GSE34899] (http://www.ncbi.nlm.nih.gov/geo/query/acc. cgi?acc=GSE34899) [74].

\section{MapMan display}

The averaged signals for a given treatment were expressed relative to those for control samples, converted to a $\log 2$ scale and displayed by use of MapMan v3.5.1 [75]. O. sativa mapping files were imported into MapMan. Rice genes represented on the Rice Oligo DNA Microarray were organized by BINS and sub-BINS for display on the schematic map of the transport overview. Gene expression was analysed by the Wilcoxon Rank Sum test with uncorrected $\mathrm{p}$ value.

\section{Semi-quantitative RT-PCR}

Total RNA was isolated from root tissues treated with 50 ppm FA for 3, 12, or 24 h by use of the RNeasy Plant
Mini kit (QIAGEN) and purified with the RNase-Free DNase Set (QIAGEN). Primer sequences are in Supporting Information (Additional file 16: Table S12). The number of PCR cycles in the experiments was adjusted to the optimal conditions. The data was shown on the basis of at least three biological replicates. Amplicons were analyzed by $1 \%$ agarose gel electrophoresis, and PCR products were sequenced.

\section{Histochemical analyses and in-gel enzyme analyses}

Histochemical detection of lipid peroxidation involved use of Schiff's reagent [76]. In brief, freshly harvested rice roots were stained with Schiff's reagent for $60 \mathrm{~min}$, which detects aldehydes originating from lipid peroxides. Then roots were rinsed with potassium sulphite solution $\left(0.5 \%[\mathrm{w} / \mathrm{v}] \quad \mathrm{K}_{2} \mathrm{~S}_{2} \mathrm{O}_{5}\right.$ prepared in $\left.0.05 \mathrm{M} \mathrm{HCl}\right)$ and maintained in the solution. The isozymes of lipoxygenase (LOX) were separated on discontinuous polyacrylamide gels (stacking gel 4.5\%, separating gel 10\%) under nondenaturing and non-reducing conditions. Proteins were electrophoretically separated at $4^{\circ} \mathrm{C}$ and $80 \mathrm{~V}$ in the stacking gel, then $120 \mathrm{~V}$ in the separating gel. Isozymes of LOX were visualized as described [77].

\section{Additional files}

Additional file 1: Figure S1. Detection of superoxide accumulation in rice roots during ferulic acid (FA) stress with nitroblue tetrazolium (NBT) staining. Rice seedling roots were treated with 50 ppm FA for 1-3 h.

Additional file 2: Figure S2. Reactive oxygen species (ROS) production and calcium accumulation in rice roots during FA stress. (A) Root samples were labeled with $10 \mu \mathrm{M} \mathrm{CM}-\mathrm{H}_{2}$ DCF-DA for $30 \mathrm{~min}$ and treated with 50 ppm FA for 1-3 h. (B) Root samples were labeled with $10 \mu \mathrm{M}$ Oregon Green 488 BAPTA-1, a calcium indicator, for $30 \mathrm{~min}$ and treated with 50 ppm FA for 1-3 h. The signals were quantified by use of ImageJ program producing histograms of signal intensity. The signal of the first sample on the panel was defined as 1.0 (arbitrary units), and other abundances were expressed relative to that value. Intensity values in each panel are color coded to represent the relative fold change in expression.

Additional file 3: Figure S3. Lipid peroxidation in rice roots and time course of the response of lipoxygenase (LOX) activity with ferulic acid (FA) treatment in rice roots. (A) FA-induced lipid peroxidation. Roots were stained with Schiff's reagent. (B) Rice roots were treated with 50 ppm FA for 3-24 h. Native polyacrylamide gel electrophoresis of root extracts containing $200 \mu \mathrm{g}$ protein.

Additional file 4: Table S1. Genes with expression responding to 50 ppm ferulic acid.

Additional file 5: Table S2. Gene ontology analysis of 972 genes upregulated with 50 ppm ferulic acid.

Additional file 6: Figure S4. Verification of microarray data by RT-PCR. The number of PCR cycles in the experiments was adjusted to the optimal conditions. The data was shown on the basis of at least three biological replicates.

Additional file 7: Table S3. Expression profiles of cell wall-related genes induced by 50 ppm ferulic acid.

Additional file 8: Table S4. Expression profiles of ROS-related genes induced by ferulic acid stress. 
Additional file 9: Table S5. Expression profiles of transporter genes induced by ferulic acid stress.

Additional file 10: Table S6. Expression profiles of phytohormonerelated genes induced by ferulic acid stress.

Additional file 11: Table S7. Expression profiles of protein kinase genes induced by ferulic acid stress.

Additional file 12: Table S8. Expression profiles of transcription factors induced by ferulic acid stress.

Additional file 13: Table S9. Expression profiles of transporter genes induced by short exposure to ferulic acid or juglone.

Additional file 14: Table S10. Expression profiles of transcription factors induced by short exposure to ferulic acid or juglone.

Additional file 15: Table S11. Expression profiles of protein kinase genes induced by short exposure to ferulic acid or juglone.

Additional file 16: Table S12. Oligonucleotide primers for semiquantitative RT-PCR.

\section{Abbreviations}

AAAP: Amino acid/auxin permease; ABC: ATP-binding cassette; AOX: Alternative oxidases; AP2/ERF: APETALA2/ET response factor: BGAL: Beta-galactosidases; $\mathrm{CM}-\mathrm{H}_{2} \mathrm{DCF}-\mathrm{DA}$ : 5-(and-6)-chlormethyl-2',7'dichlordihydrofluorescein diacetate, acetyl ester;

DCF: Dihydrodichlorofluorescein; DMT: Drug/metabolite transporter; DRTF: The Database of Rice Transcription Factors; ET: Ethylene; EXP: Expansins; FA: Ferulic acid; FDR: False discovery rate; GH17: Glycoside hydrolases 17; GH18: Yieldins; GO: Gene ontology; GPx: Glutathione peroxidase; GR: Glutathione reductase; Grx: Glutaredoxins; GST: Glutathione Stransferases; JA: Jasmonic acid; LOX: Lipoxygenase; LRR-VIII: Leucine-rich repeat VIII; MDAR: Monodehydroascorbate reductase; MFS: Major facilitator superfamily; PAE: Pectin acetylesterases; PAL: Phenylalanine ammonia-lyase; POD: Peroxidase; POT: Proton-dependent oligopeptide transporter; Prx: Class III peroxidase; PrxR: Peroxiredoxin; P-ATPase: P-type ATPase; Rboh: Respiratory burst oxidase homolog; RLCK: Receptor-like cytoplasmic kinase;

RLK: Receptor-like kinase; ROS: Reactive oxygen species; TFs: Transcription factors; Trx: Thioredoxin; XTH: Xyloglucan endotransglycosylases/hydrolases; ZIM: Zinc-finger protein expressed in inflorescence meristem.

\section{Competing interests}

The authors declare that they have no competing interests.

\section{Authors' contributions}

WCC and YAC carried out the microarray studies and drafted the manuscript. YCH carried out the RT-PCR. SFF, CHC, NNT and YCC participated in the design of the study. $\mathrm{HJH}$ conceived the study, participated in its design and coordination, and helped to draft the manuscript. All authors read and approved the final manuscript.

\section{Acknowledgments}

This work was supported by research grants from the National Science Council (NSC 98-2621-B-006-003-MY3 and NSC 101-2621-B-006-001-MY3) and the Ministry of Education, Taiwan (Aim for the Top University Project B024). Agilent DNA microarray assays were performed by the DNA Microarray Core Laboratory in the Institute of Plant and Microbial Biology, Academia Sinica. Expression profiling and data mining used the system provided by the Bioinformatics Core for Genomic Medicine and Biotechnology Development at National Cheng-Kung University, supported by a National Science Counci grant (NSC 97-3112-B-006-011).

\section{Author details}

'Department of Life Sciences, National Cheng Kung University, No. 1 University Rd. 701, Tainan, Taiwan, ROC. ${ }^{2}$ Department of Biological Sciences, National Sun Yat-Sen University, No. 70, Lienhai Rd. 80424, Kaohsiung, Taiwan, ROC. ${ }^{3}$ Department of Biology, National Changhua University of Education, No. 1, Jin-De Road, Changhua City 500, Taiwan, ROC. ${ }^{4}$ Graduate Institute of Ecology and Evolutionary Biology, College of Life Sciences, China Medical University, 91, Hsueh-Shih Road, Taichung 404, Taiwan, ROC.
Received: 25 May 2012 Accepted: 2 May 2013

Published: 25 May 2013

\section{References}

1. Singh HP, Batish DR, Kohli RK: Autotoxicity: Concept, organisms, and ecological significance. Crit Rev Plant Sci 1999, 18:757-772.

2. Chou CH: Allelopathy and sustainable agriculture. In Allelopathy: Organisms, Process and Applications, ACs symposium series 582. Edited by Inderjit, Dakshini KM, Einhellig FA. Washington, DC: American Chemical Society; 1995:211-223.

3. Chou CH: Roles of allelopathy in plant biodiversity and sustainable agriculture. Crit Rev Plant Sci 1999, 18:609-636.

4. Miller DA: Allelopathy in forage crop systems. Agron J 1996, 88:854-859.

5. Chou CH, Lin HJ: Autointoxication mechanism of Oryza sativa I. Phytotoxic effects of decomposing rice residues in soil. J Chem Ecol 1976, 2:353-367.

6. Seal AN, Haig T, Pratley JE: Evaluation of putative allelochemicals in rice root exudates for their role in the suppression of arrowhead root growth. J Chem Ecol 2004, 30:1663-1678.

7. Belz RG: Allelopathy in crop/weed interactions - an update. Pest Manag Sci 2007, 63:308-326.

8. Whitehead DC: Identification of p-hydroxybenzoic vanillie., p-coumaric and ferulic acids in soils. Nature 1964, 202:417-418.

9. Yang CM, Lee CN, Chou CH: Effects of three allelopathic phenolics on chlorophyll accumulation of rice (Oryza sativa) seedlings: I. Inhibition of supply-orientation. Bot Bull Acad Sin 2002, 43:299-304.

10. Holappa LD, Blum U: Effects of exogenously applied ferulic acid, a potential allelopathic compound, on leaf growth, water utilization, and endogenous abscisic acid levels of tomato, cucumber, and bean. $J$ Chem Ecol 1991, 17:865-886.

11. Blum U, Rebbeck J: Inhibition and recovery of cucumber roots given multiple treatments of ferulic acid in nutrient culture. J Chem Ecol 1989, 15:917-928.

12. Pramanik MHR, Nagai M, Asao T, Matsui Y: Effects of temperature and photoperiod on phytotoxic root exudates of cucumber (Cucumis sativus) in Hydroponic culture. J Chem Ecol 2000, 26:1953-1967.

13. Bergmark $\mathrm{CL}$, Jackson WA, Volk RJ, Blum U: Differential inhibition by ferulic acid of nitrate and ammonium uptake in Zea mays L. Plant Physiol 1992, 98:639-645.

14. Booker FL, Blum U, Fiscus EL: Short-term effects of ferulic acid on ion uptake and water relations in cucumber seedlings. J Exp Bot 1992, 43:649-655.

15. Lyu SW, Blum U: Effects of ferulic acid, an allelopathic compound, on net $\mathrm{P}, \mathrm{K}$, and water uptake by cucumber seedlings in a split-root system. J Chem Ecol 1990, 16:2429-2439.

16. Baziramakenga R, Leroux GD, Simard RR: Effects of benzoic and cinnamic acids on membrane permeability of soybean roots. J Chem Ecol 1995, 21:1271-1285

17. Politycka B: Phenolics and the activities of phenylalanine ammonia-lyase, phenol- $\beta$-glucosyltransferase and $\beta$-glucosidase in cucumber roots as affected by phenolic allelochemicals. Acta Physiol Plant 1998, 20:405-410.

18. Devi SR, Prasad MNV: Ferulic acid mediated changes in oxidative enzymes of maize seedlings: implications in growth. Biol Plant 1996, 38:387-395.

19. liyama K, Lam TBT, Stone BA: Phenolic acid bridges between polysaccharides and lignin in wheat internodes. Phytochemistry 1990, 29:733-737.

20. Sanchez M, Pena MJ, Revilla G, Zarra I: Changes in dehydrodiferulic acids and peroxidase activity against ferulic acid associated with cell walls during growth of Pinus pinaster hypocotyl. Plant Physiol 1996, 111:941-946.

21. dos Santos WD, Ferrarese ML, Nakamura CV, Mourão KS, Mangolin CA, Ferrarese-Filho O: Soybean (Glycine max) root lignification induced by ferulic acid. The possible mode of action. J Chem Ecol 2008, 34:1230-1241.

22. Ding J, Sun Y, Xiao CL, Shi K, Zhou YH, Yu JQ: Physiological basis of different allelopathic reactions of cucumber and figleaf gourd plants to cinnamic acid. J Exp Bot 2007, 58:3765-3773.

23. Huang LF, Song LX, Xia XJ, Mao WH, Shi K, Zhou YH, Yu JQ: Plant-soil feedbacks and soil sickness: from mechanisms to application in agriculture. J Chem Ecol 2013. doi:10.1007/s10886-013-0244-9 [Epub ahead of print]. 
24. Apel K, Hirt H: Reactive oxygen species: metabolism, oxidative stress, and signal transduction. Annu Rev Plant Biol 2004, 55:373-399.

25. Dunand $C$, Crèvecoeur $M$, Penel C: Distribution of superoxide and hydrogen peroxide in Arabidopsis root and their influence on root development: possible interaction with peroxidases. New Phytol 2007, 174:332-341.

26. Neill SJ, Desikan R, Clarke A, Hurst RD, Hancock JT: Hydrogen peroxide and nitric oxide as signalling molecules in plants. J Exp Bot 2002, 53:1237-1247.

27. Hepler PK: Calcium: a central regulator of plant growth and development. Plant Cell 2005, 17:2142-2155.

28. Foreman J, Demidchik V, Bothwell JH, Mylona P, Miedema H, Torres MA, Linstead P, Costa S, Brownlee C, Jones JD, Davies JM, Dolan L: Reactive oxygen species produced by NADPH oxidase regulate plant cell growth. Nature 2003, 422(6930):442-446.

29. Chon SU, Choi SK, Jung S, Jang HG, Pyo BS, Kim SM: Effects of alfalfa leaf extracts and phenolic allelochemicals on early seedling growth and root morphology of alfalfa and barnyard grass. Crop Prot 2002, 21:1077-1082.

30. Chon SU, Kim JD: Biological activity and quantification of suspected allelochemicals from alfalfa plant parts. J Agron Crop Sci 2002, 188:281-285.

31. Duke SO, Baerson SR, Pan Z, Kagan IA, Sánchez-Moreiras A, Reigosa MJ, Pedrol N, Schulz M: Genomic approaches to understanding allelochemical effects on plants. In Allelopathy in Sustainable Agriculture and Forestry. Edited by Zeng RS, Mallik AU, Luo SM. New York, NY: Springer; 2008:157-167.

32. Baerson SR, Sanchez-Moreiras A, Pedrol-Bonjoch N, Schulz M, Kagan IA Agarwal AK, Reigosa MJ, Duke SO: Detoxification and transcriptome response in Arabidopsis seedlings exposed to the allelochemical benzoxazolin-2(3H)-one. J Biol Chem 2005, 280:21867-21881.

33. Golisz A, Sugano M, Fujii Y: Microarray expression profiling of Arabidopsis thaliana $\mathrm{L}$. in response to allelochemicals identified in buckwheat. J Exp Bot 2008, 59:3099-3109.

34. Golisz A, Sugano M, Hiradate S, Fujii Y: Microarray analysis of Arabidopsis plants in response to allelochemical I-DOPA. Planta 2011, 233:231-240.

35. Chi WC, Fu SF, Huang TL, Chen YA, Chen CC, Huang HJ: Identification of transcriptome profiles and signaling pathways for the allelochemical juglone in rice roots. Plant Mol Biol 2011, 77:591-607.

36. Kuwatsuka S, Shindo H: Behavior of phenolic substances in the decaying process of plants: I. Identification and quantitative determination of phenolic acids in rice straw and its decayed product by gas chromatography. Soil Sci Plant Nutr 1973, 19:219-227.

37. Werner T: Bioinformatics applications for pathway analysis of microarray data. Curr Opin Biotechnol 2008, 19:50-54.

38. Bogatek R, Gniazdowska A: ROS and phytohormones in plant-plant allelopathic interaction. Plant Signal Behav 2007, 2:317-318.

39. Xu Y, Chang P, Liu D, Narasimhan ML, Raghothama KG, Hasegawa PM, Bressan RA: Plant defense genes are synergistically induced by ethylene and methyl jasmonate. Plant Cell 1994, 6:1077-1085.

40. Hua J, Meyerowitz EM: Ethylene responses are negatively regulated by a receptor gene family in Arabidopsis thaliana. Cell 1998, 94:261-271.

41. Staswick PE, Su W, Howell SH: Methyl jasmonate inhibition of root growth and induction of a leaf protein are decreased in an Arabidopsis thaliana mutant. Proc Natl Acad Sci USA 1992, 89:6837-6840.

42. Sato $Y$, Takehisa $H$, Kamatsuki K, Minami H, Namiki N, Ikawa H, Ohyanagi $H$, Sugimoto K, Antonio BA, Nagamura Y: RiceXPro version 3.0: expanding the informatics resource for rice transcriptome. Nucleic Acids Res 2013, 41(Database issue):D1206-D1213.

43. Christensen JH, Bauw G, Gjesing Welinder K, Van Montagu M, Boerjan W: Purification and characterization of peroxidases correlated with lignification in poplar xylem. Plant Physio/ 1998, 118:125-135.

44. Cosgrove DJ: Relaxation in a high-stress environment: the molecular bases of extensible cell walls and cell enlargement. Plant Cell 1997, 9:1031-1041.

45. Gniazdowska A, Bogatek R: Allelopathic interactions between plants. Multi site action of allelochemicals. Acta Physiol Plant 2005, 27:395-407.

46. Lee $\Pi$ T, Starratt AN, Jevnikar JJ: Regulation of enzymic oxidation of indole-3-acetic acid by phenols: Structure-activity relationships. Phytochemistry 1982, 21:517-523.

47. Pang A, Catesson A, Francesch C, Rolando C, Goldberg R: On substrate specificity of peroxidases involved in the lignification process. J Plant Physiol 1989, 135:325-329.
48. Saijo Y, Hata S, Kyozuka J, Shimamoto K, Izui K: Over-expression of a single $\mathrm{Ca} 2+-$ dependent protein kinase confers both cold and salt/drought tolerance on rice plants. Plant J 2000, 23:319-327.

49. Martín ML, Busconi L: A rice membrane-bound calcium-dependent protein kinase is activated in response to low temperature. Plant Physiol 2001, 125:1442-1449.

50. Dixon RA, Harrison MJ, Lamb CJ: Early events in the activation of plant defense responses. Annu Rev Phytopathol 1994, 32:479-501.

51. Rea PA: Mrp subfamily abc transporters from plants and yeast. J Exp Bot 1999, 50(Special Issue):895-913

52. Schwacke R, Grallath S, Breitkreuz KE, Stransky E, Stransky H, Frommer WB, Rentsch D: LeProT1, a transporter for proline, glycine betaine, and gamma-amino butyric acid in tomato pollen. Plant Cell 1999, 11:377-392.

53. Hanson AD, Hitz W: Metabolic responses of mesophytic plants to water deficits. Annu Rev Plant Physiol 1982, 33:163-203.

54. Serrano R: Salt tolerance in plants and microorganisms: toxicity targets and defense responses. Int Rev Cytol 1996, 165:1-52.

55. Ashraf M, Foolad MR: Roles of glycine betaine and proline in improving plant abiotic stress resistance. Environ Exp Bot 2007, 59:206-216.

56. Chen TH, Murata N: Glycinebetaine: an effective protectant against abiotic stress in plants. Trends Plant Sci 2008, 13:499-505.

57. Boller T, Felix G: A renaissance of elicitors: perception of microbeassociated molecular patterns and danger signals by pattern-recognition receptors. Annu Rev Plant Biol 2009, 60:379-406.

58. Lehti-Shiu MD, Zou C, Hanada K, Shiu SH: Evolutionary history and stress regulation of plant receptor-like kinase/pelle genes. Plant Physiol 2009, 150:12-26.

59. Gish LA, Clark SE: The RLK/Pelle family of kinases. Plant J 2011, 66:117-127.

60. Shin R, Park JM, An JM, Paek KH: Ectopic expression of Tsi1 in transgenic hot pepper plants enhances host resistance to viral, bacterial, and oomycete pathogens. Mol Plant Microbe Interact 2002, 15:983-989.

61. Agarwal PK, Agarwal P, Reddy MK, Sopory SK: Role of DREB transcription factors in abiotic and biotic stress tolerance in plants. Plant Cell Rep 2006, 25:1263-1274.

62. Park MR, Yun KY, Mohanty B, Herath V, Xu F, Wijaya E, Bajic VB, Yun SJ, De Los Reyes BG: Supra-optimal expression of the cold-regulated OsMyb4 transcription factor in transgenic rice changes the complexity of transcriptional network with major effects on stress tolerance and panicle development. Plant Cell Environ 2010, 33:2209-2230.

63. Wang $H$, Hao J, Chen X, Hao Z, Wang X, Lou Y, Peng Y, Guo Z: Overexpression of rice WRKY89 enhances ultraviolet $B$ tolerance and disease resistance in rice plants. Plant Mol Biol 2007, 65:799-815.

64. Ye H, Du H, Tang N, Li X, Xiong L: Identification and expression profiling analysis of TIFY family genes involved in stress and phytohormone responses in rice. Plant Mol Biol 2009, 71:291-305.

65. Huang TL, Huang HJ: ROS and CDPK-like kinase-mediated activation of MAP kinase in rice roots exposed to lead. Chemosphere 2008, 71:1377-1385.

66. Ouyang S, Zhu W, Hamilton J, Lin H, Campbell M, Childs K, Thibaud-Nissen F, Malek RL, Lee Y, Zheng L, Orvis J, Haas B, Wortman J, Buell CR: The TIGR rice genome annotation resource: improvements and new features. Nucl Acids Res 2007, 35(suppl_1):D883-D887.

67. Du Z, Zhou X, Ling Y, Zhang Z, Su Z: agriGO: a GO analysis toolkit for the agricultural community. Nucleic Acids Res 2010, 38(suppl 2):W64-W70.

68. Dardick C, Chen J, Richter T, Ouyang S, Ronald P: The rice kinase database. A phylogenomic database for the rice kinome. Plant Physiol 2007, 143:579-586.

69. Gao G, Zhong Y, Guo A, Zhu Q, Tang W, Zheng W, Gu X, Wei L, Luo J: DRTF: a database of rice transcription factors. Bioinformatics 2006, 22:1286-1287

70. Passardi F, Theiler G, Zamocky M, Cosio C, Rouhier N, Teixera F, MargisPinheiro M, loannidis V, Penel C, Falquet L, Dunand C: PeroxiBase: The peroxidase database. Phytochemistry 2007, 68:1605-1611.

71. Girke T, Lauricha J, Tran H, Keegstra K, Raikhel N, The Cell Wall Navigator database: A systems-based approach to organism-unrestricted mining of protein families involved in cell wall metabolism. Plant Physiol 2004, 136:3003-3008.

72. Ren Q, Kang KH, Paulsen IT: TransportDB: a relational database of cellular membrane transport systems. Nucleic Acids Res 2004, 32(suppl 1):D284-D288.

73. Agresti A: A survey of exact inference for contingency tables. Stat Sci 1992, 7:131-153. 
74. Edgar R, Domrachev M, Lash AE: Gene Expression Omnibus: NCBI gene expression and hybridization array data repository. Nucleic Acids Res 2002, 30:207-210.

75. Usadel B, Nagel A, Thimm O, Redestig H, Blaesing OE, Palacios-Rojas N Selbig J, Hannemann J, Piques MC, Steinhauser D, Scheible WR, Gibon Y, Morcuende R, Weicht D, Meyer S, Stitt M: Extension of the visualization tool MapMan to allow statistical analysis of arrays, display of coresponding genes, and comparison with known responses. Plant Physiol 2005, 138:1195-1204.

76. Pompella A, Maellaro E, Casini AF, Comporti M: Histochemical detection of lipid peroxidation in the liver of bromobenzene-poisoned mice. Am J Pathol 1987, 129:295-301.

77. Wang YS, Yang ZM: Nitric oxide reduces aluminum toxicity by preventing oxidative stress in the roots of Cassia tora L. Plant Cell Physiol 2005, 46:1915-1923.

doi:10.1186/1471-2164-14-351

Cite this article as: Chi et al:: Autotoxicity mechanism of Oryza sativa: transcriptome response in rice roots exposed to ferulic acid. BMC

Genomics 2013 14:351.

\section{Submit your next manuscript to BioMed Central and take full advantage of:}

- Convenient online submission

- Thorough peer review

- No space constraints or color figure charges

- Immediate publication on acceptance

- Inclusion in PubMed, CAS, Scopus and Google Scholar

- Research which is freely available for redistribution 